\title{
Cloning and Characterization of a Putative Antifungal Peptide Gene (Pm-AMP1) in Pinus monticola
}

\author{
A. K. M. Ekramoddoullah, J.-J. Liu, and A. Zamani
}

Pacific Forestry Centre, Canadian Forest Service, Natural Resources Canada, Victoria, B.C. V8Z 1M5 Canada. Accepted for publication 21 September 2005.

\begin{abstract}
Ekramoddoullah, A. K. M., Liu, J.-J., and Zamani, A. 2006. Cloning and characterization of a putative antifungal peptide gene $(P m-A M P 1)$ in Pinus monticola. Phytopathology 96:164-170.

We have been working on proteins that are involved in the defense response of western white pine (WWP) (Pinus monitcola) to the blister rust fungus Cronartium ribicola. Our objective was to identify candidate genes that could be used for improving resistance of WWP to this rust pathogen. During proteomic analysis of bark proteins extracted from WWP trees exhibiting slow-canker-growth (SCG) resistance, a 10.6-kDa peptide, termed Pm-AMP1, was found to be enriched at the receding canker margin. The cDNA encoding this peptide was cloned and charac-

cDNA has a 50\% homology with MiAMP1, a broad-spectrum antifungal protein isolated from Macadamia integrifolia. Based on the deduced amino acid sequence, an antibody was produced against the Pm-AMP1. Immunochemical quantification of the Pm-AMP1 in bark samples of susceptible WWP trees revealed this protein to be barely detectable in the cankered tissues, but occurring in higher concentrations in healthy tissues away from canker margins. Foliage of SCG-resistant trees contained higher concentrations of the Pm-AMP1 than foliage from susceptible cankered trees. Both wounding and methyl jasmonate treatment of WWP needles induced the expression of this protein, further supporting its putative role as a defense response protein.
\end{abstract} terized. A BLASTX search revealed that the Pm-AMP1 encoded by its
Additional keywords: electrophoresis, western immunoblot.
Western white pine (WWP) (Pinus monticola Dougl. Ex D. Don) is an economically important, fast-growing species that is widely distributed throughout the Pacific Northwest and California. The high stumpage value of this pine and its excellent genetic resistance to root rot by Inonotus tomentosus, Armillaria ostoyae, and Phellinus weirii make WWP an attractive species for use in reforestation. However, the potential for commercialization has not yet been realized, because of its susceptibility to infection by white pine blister rust (Cronartium ribicola J.C. Fisch.). This rust is an ecologically and economically significant disease, and has resulted in reduced plantation of WWP and other five-needle pines (15).

Because almost all North American WWP is susceptible to C. ribicola, obtaining genetic resistance to C. ribicola and maintaining genetic diversity among production populations used in WWP-breeding programs are important objectives. Genetic resistance to white pine blister rust varies widely among WWP populations. Several types of WWP genetic resistance to white pine blister rust, including slow-canker-growth (SCG) (11) and major dominant gene resistance $(\mathrm{Cr} 2)(13)$, have been identified after multiyear genetic-breeding studies. SCG resistance is a durable resistance expressed in WWP seedling stems; it restricts the infection area, and cankers eventually heal (11). Different kinds of SCG resistance have been observed, suggesting multiple genes may control it (7).

In a dominant gene-mediated resistance of white pine, infection is restricted to the needle (which is the target of blister rust patho-

Corresponding author; A. K. M. Ekramoddoullah

E-mail address: aekramoddoul@nrcan.gc.ca

This work was supported by Canadian Forest Service Genomic and British Columbia Forest Innovation Funds.

DOI: $10.1094 /$ PHYTO-96-0164

C 2006 Her Majesty the Queen in right of Canada, Natural Resources Canada, Canadian Forest Service gen attack) by the hypersensitive response. In SCG resistance, infection spreads from the needle to the bark and develops into cankers, but with time these cankers heal. In our breeding program, four types of SCG based on canker size and shape are recognizable (7). Little is known about the physiology or biochemical nature of SCG mechanisms, although it has been shown that the delayed onset of this resistance is associated with longer field survival of infected seedlings. This mechanism has a heritability value of 0.21 to 0.46 , making the phenotype attractive to tree breeders (9). Unfortunately, screening of seedlings for SCG resistance is a long-term task that takes 6 to 7 years. A WWPbreeding program requires increased understanding of the plant's defense mechanisms against $C$. ribicola, as well as a search for potential molecular markers for marker-assisted selection.

With advancements in molecular techniques, an increasing number of defense response genes have been characterized in several plant-pathogen systems including conifers (7). Proteins encoded by these genes are usually pathogenesis-related (PR) proteins or low-molecular-weight antimicrobial peptides (AMPs) that may act in concert to limit the growth of pathogens in infected hosts. In our laboratory, we have characterized several PR proteins that are up-regulated in the white pine blister rust pathosystem. While investigating bark proteins associated with SCG in WWP, we discovered a 10.6-kDa protein, termed Pm-AMP1, in SCG-resistant trees (3). A partial N-terminal sequence was determined. At the time, the sequence revealed no homology with known protein sequences in the databank. The N-terminal sequence was recently searched against a database and showed significant homology with AMP MiAMP1 isolated from Macademia integrifolia (16). This highly basic AMP inhibited several major taxonomic groups of microbes and showed no toxic effects toward the host plant or animal cell, making it a potentially important candidate in the design of new fungicides (17). More recently, an antimicrobial gene (Sp-AMP) with homology to MiAMP1 has been isolated in Scots pine showing elevated mRNA transcript levels in necrotic root tissue (1). 
AMPs are present in most plant species (2). These peptides contain even numbers of cysteines (four, six, or eight) that form disulfide bridges, thus providing high stability to the peptides. Based on homologies at the primary structure level, plant AMPs can be classified into distinct families including thionins, defensins, lipid transfer proteins, and hevein- and knottin-type AMPs. Detailed three-dimensional structure information has been obtained for one or more members of these peptide families. All AMPs studied to date appear to exert their antimicrobial effects at the level of the plasma membrane of the target microorganism, but different peptide types probably act via different mechanisms. Plant defensins, thionin, and lipid transfer proteins have been observed to be induced upon infection of plants by pathogens, which suggests that they have an active role in host defense. In some cases, overexpression of these peptides can lead to enhanced resistance. Although MiAPM1 contains six cysteine residues, it has no homology with these distinct families of AMPs. In vitro studies showed MiAPM1 has broad-spectrum antimicrobial activity. Interestingly, the structure of MiAMP1 bears remarkable similarity to a yeast-killing toxin from Wiiliopsis mrakii, which inhibits $\beta$-glucan synthesis (17). However, the role of MiAPM1 in host defense response remains unknown.

In the present study, we cloned and characterized Pm-AMP1. Using an anti-Pm-AMP1 antibody as a probe, we examined the levels of Pm-AMP1 in infected WWP trees.

\section{MATERIALS AND METHODS}

Plant materials and experimental treatments. Bark samples (all tissues outside the xylem, including periderm, phloem, and the cambial zone) were collected from resistant (i.e., canker-free) and susceptible (i.e., cankered) mature WWP grown in plantation 4/plot B (10) located at Lens Creek, Vancouver Island, British Columbia. Selection for resistance (clones G-8, G-161, and B643) was based upon so-called "mature resistance" (R. S. Hunt, Canadian Forest Service, Victoria, B.C., personal communication). Such clones were difficult to infect in a diseased garden (i.e., when grown with $C$. ribicola-infected Ribes sp. [W. A. Porter, 1960, Canada Department of Agriculture, Victoria, B.C., unpublished data]), and their ramets lacked cankers. Similarly tested susceptible clones (G-27 and 6149) were also sampled, and ramets from these had four or more cankers. Ramets were 31 to 33 years old in 1991. All samples were taken from healthy trunk bark in April 1991, February 1993, October 1993, and May 1994.

Two-year-old susceptible WWP seedlings (20 cankered individuals) and resistant seedlings, which displayed slow canker growth (23 individuals), were inoculated in August 1992 by suspending over the seedlings Ribes leaves (10) infected with a composite inoculum from six coastal British Columbia sources of the rust fungus. The seedlings were grown outdoors under natural day length and temperature conditions at Cowichan Lake Research Station, Vancouver Island. The following winter, the seedlings were transferred from Styrofoam blocks to 1-gallon $\left(4.5 \mathrm{dm}^{3}\right)$ pots. Both susceptible and SCG seedlings were from families undergoing screening for blister rust resistance for coastal British Columbia (4). Samples of bark, twigs, and foliage were collected from these seedlings in summer (July 1995) and winter (February 1996).

The chemical treatment with methyl jasmonate and the wounding treatment were performed on fully developed, current-year needles collected from several seedlings grown from a resistant $\left(\mathrm{Cr}_{2} / \mathrm{cr}_{2}\right)$ seed lot. The above treatments were carried out as described previously (14). Each treatment was repeated three times. Each time, tissue samples were taken from three individual seedlings, frozen in liquid nitrogen, and stored at $-80^{\circ} \mathrm{C}$ until analyzed.

Cloning of WWP cDNA encoding Pm-AMP1. RNA extraction from WWP needle tissues was carried out using a standard protocol (14). Reverse transcription-polymerase chain reaction (PCR) was used to clone WWP cDNA encoding Pm-AMP1. The first-strand cDNA was synthesized using a SMART cDNA Library Construction Kit (Clontech Laboratories, Inc., Palo Alto, CA) following the manufacturer's instructions. According to the $\mathrm{N}$-terminal amino acid sequence of the $10.6-\mathrm{kDa}$ protein (3; accession no. P83880), one reverse primer, 10.6K-A (5'-(A/G)TA (A/T/C/G)C(T/G) (A/T/C/G)GC (A/G)TT (A/G)TG (A/G)TT (A/G)TT-3'), was designed. With $10.6 \mathrm{~K}-\mathrm{A}$ primer and PCR 5' primer from the SMART cDNA Library Construction Kit (Clontech Laboratories, Inc.), 5'-rapid amplification of cDNA ends (RACE) was performed to clone the $5^{\prime}$ end partial cDNA sequence of the $10.6-\mathrm{kDa}$ protein including the $5^{\prime}$-untranslated region (5'-UTR) and a partial coding region of the $\mathrm{N}$ terminus. A forward primer, $10.6 \mathrm{~K}-\mathrm{F}$ ( $5^{\prime}$-ACT CAC ACC TTA ATA TCC TGA TCC-3'), was designed and synthesized based on 5'-UTR sequence from the above $5^{\prime}$-RACE. To clone the full-length cDNA of the $10.6-\mathrm{kDa}$ protein, $3^{\prime}$-RACE was performed using primer $10.6 \mathrm{~K}-\mathrm{F}$ and oligo $(\mathrm{dT})_{30}$.

PCR was performed with a PCR Master Mix Kit (Qiagen Inc., Mississauga, ON, Canada) using first-strand cDNA as template in a final volume of $50 \mu \mathrm{l}$ on a Perkin-Elmer Themocycler (Applied Biosystems, Foster City, CA). For 5'-RACE, thermal cycling conditions consisted of an initial denaturation step at $94^{\circ} \mathrm{C}$ for $30 \mathrm{~s}$, followed by 35 cycles of denaturation at $94^{\circ} \mathrm{C}$ for $30 \mathrm{~s}$, and primer annealing at $50^{\circ} \mathrm{C}$ for $1.5 \mathrm{~min}$ and primer extension at $72^{\circ} \mathrm{C}$ for $1.5 \mathrm{~min}$ with a final 10 -min extension at $72^{\circ} \mathrm{C}$. Thermal cycling conditions for $3^{\prime}$-RACE were the same as those for $5^{\prime}$ $\mathrm{RACE}$, except that primer annealing occurred at $60^{\circ} \mathrm{C}$ for $1 \mathrm{~min}$. After agarose gel fractionation, the amplified cDNA fragments with expected sizes were purified and cloned into pGEM-T easy vector (Promega, Madison, WI). Plasmid construction and manipulation were carried out using standard methods (18).

DNA sequencing and computer analysis. DNA sequencing of cDNA clones were determined on both strands on a DNA sequencer (ABI310; Applied Biosystems) using a Thermo-cycle sequence kit (Amersham Biosciences Corporation, Piscataway, NJ) with T7 and SP6 primers and other internal primers as needed, according to the manufacturer's instructions. DNA sequence data were assembled and analyzed using BLAST, ClustalW, and ORFfinder network services at the National Center for Biotechnology Information (NCBI).

Sodium dodecyl sulfate-polyacrylamide gel electrophoresis and western immunoblot analysis. Total proteins were extracted from plant organs and quantified according to procedures described elsewhere (5). Proteins were separated using sodium dodecyl sulfate-polyacrylamide gel electrophoresis described by Ekramoddoullah et al. (6), with equal protein loading per lane. For western blot analysis, rainbow molecular-weight standard markers (14.3 to $220 \mathrm{kDa}$ ) were used (Bio-Rad Laboratories, Mississauga, Ontario, Canada). Separated proteins were transferred onto an immobilon-P membrane (Millipore Corporation, Bedford, MA) following a standard protocol (6). A polyclonal antibody was raised in rabbits against the synthetic polypeptide with an antigenic region (H-YNTDNC(acetomidomethyl) KGVAQTRFSSSVNQAC-NH ${ }_{2}$ ) within the Pm-AMP1 peptide. Immunological detection of protein blots was carried out as described previously (6). The scanning, detection, and quantification of the blots were performed using a GS-800 Imaging Densitometer (Bio-Rad Laboratories) with Quantity One software (version 4.4, Bio-Rad Laboratories) according to the instruction manual. The protein level detected by western immunoblot analysis was calculated based on the optical density of all pixels within the band boundary, and expressed in optical density units $\times$ millimeters.

Statistical analysis. A two-way analysis of variance (ANOVA) for independent samples was used to assess significance in mean Pm-AMP1 content between various susceptible and SCG-resistant WWP tissues due to season and pathogen infection at $P<$ 
0.05. Tukey's multiple range comparison test was carried out to determine the absolute difference between two sample means required for significance at $P<0.05$. The VassarStats website for statistical computation was used for the analysis.

\section{RESULTS}

Characterization of $P \boldsymbol{m}-\boldsymbol{A M P 1}$ cDNA. The nucleotide and deduced amino acid sequence of $P m-A M P 1$ cDNA has been deposited under GenBank accession no. AY596276. The nucleotide sequence has two in-frame stop codons, one at the end of the coding region and the other in the 5 '-UTR, suggesting that the cloned cDNA of $P m-A M P 1$ has a complete open reading frame. It also has poly-A signals in the 3 '-UTR. The open reading frame consists of 105 amino acids containing a signal peptide of 26 amino acid residues. The deduced molecular mass of the mature peptide is about $8.6 \mathrm{kDa}$ with a predicted $\mathrm{pI}$ of 8.6. The mature PmAMP1 has an even number (six) of cysteine residues. The Nterminal sequence of Pm-AMP1 mature protein was confirmed by amino acid sequence analysis reported previously (3).

A comparison of the deduced amino acid sequences of PmAMP1, four clones of Sp-AMPs (1) and MiAMP1 (Fig. 1) showed 51\% homology between Pm-AMP1 and MiAMP1; the strongest homology (89 to 93\%) was observed between Pm-AMP1 and Sp-AMPs. All six cysteine residues are conserved among these AMPs. Pm-AMP1 also shared low identity (15\%) to Tulipa gesneriana thionin Thi4-1 (GenBank accession no. X81710). Analyses of posttranslational modifications with software programs in ExPASy (ExPASy is provided online by the Swiss Institute of Bioinformatics [SIB]) demonstrated that there is neither an $\mathrm{N}$-glycosylation site nor an $\mathrm{O}$-GalNAc glycosylation site in PmAMP1. However, four potential phosphorylation sites were identified in Pm-AMP1, at positions Y34, S60, S61, and S62 of the mature peptide.

Within its primary and secondary structures (Fig. 2), Pm-AMP1 shared two common features with other well-characterized membrane-acting antifungal proteins: a positive net charge under physiological conditions (pI 8.6 for Pm-AMP1) that facilitates interaction with negatively charged microbial surfaces, and amphipathic structures which permit incorporation into microbial membranes. In terms of secondary structure, using the software package SWISS-MODEL (SWISS-MODEL provided online by SIB) (19), Pm-AMP1 was predicted to consist of seven $\beta$-strands forming two antiparallel $\beta$-sheets. Using the same software program, the 3-D structure of Pm-AMP1 (Fig. 2) was simulated and determined to be very similar to that of MiAMP1. From the Nterminal, the first, second, and fourth $\beta$-strands (amino acid resi- due 2 to 7,16 to 18 , and 32 to 37 , respectively) constitute the first $\beta$-sheet, and the third, fifth, sixth, and seventh $\beta$-strands (amino acid residue 22 to 26,42 to 46,57 to 59 , and 73 to 78 , respectively) make up the second $\beta$-sheet. These two $\beta$-sheets were predicted to be stabilized by three disulfide bridges between the six conserved cysteines.

Strategy for, and production of, an antibody probe specific to Pm-AMP1. To study the potential role of Pm-AMP1 in the

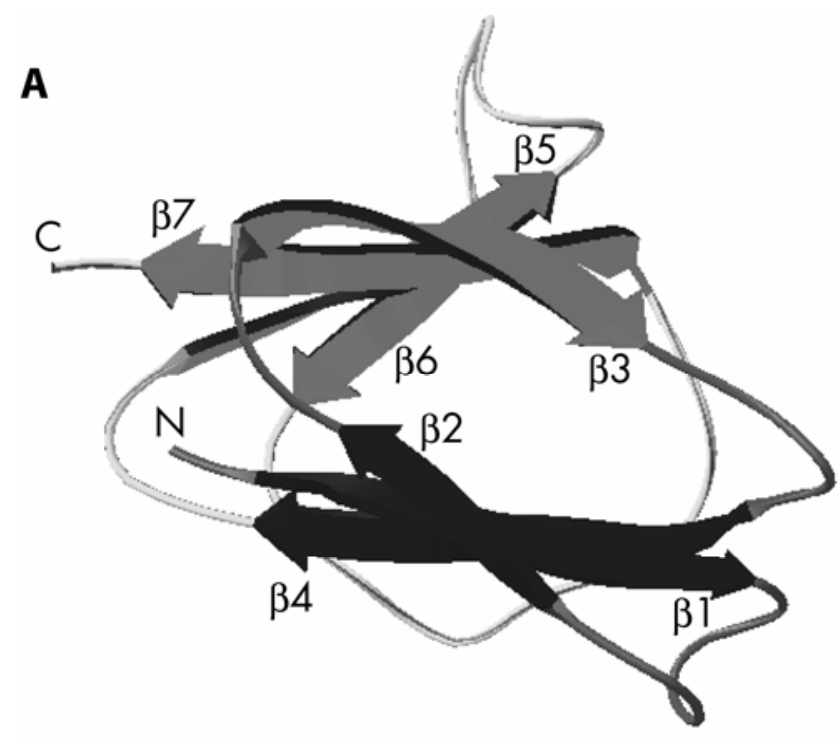

B

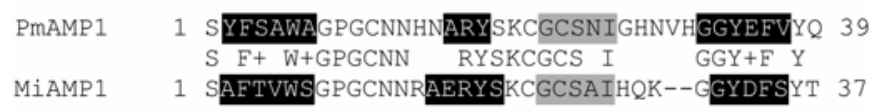

PMAMP1 40 GQTAAAYNTDNCKGVAQTRESSSVNQACSNFGWKSVFIQC 79 GQTAA YN C GVA TRF SS +AC+ FGWKS+FIQC

MIAMP1 38 GQTAALYNQAGCSGVAHTRFGSSA-RACNPFGWKSIFIQC 76

Fig. 2. Predicted structure of Pm-AMP1. A, The three-dimensional structure of Pm-AMP1 simulated using SWISS-MODEL software package. Its two $\beta$ sheets are represented by black and gray arrows representing three or four $\beta$ strands, respectively. The structure was drawn with Deep View Swiss-Pdb Viewer software package (19). B, The alignment of two antifungal protein sequences is shown. Black shaded $\beta$-strands form sheet one, whereas gray shaded $\beta$-strands form sheet two.

\begin{tabular}{|c|c|}
\hline PmAMP1 & METKRLAYVMFVLVCLFLAMAQPSQASYFSAWAGPGCNNHNARYSKCGCS \\
\hline Sp-AMP2 & METKRLAYVMFVLVCLFLAMAQPSQGSYFTAWAGPGCNNHAARYSKCGCS \\
\hline $\mathrm{Sp}-\mathrm{AMP} 4$ & METKRLAYVMFVLVCLFLAMAQPSQGSYFTAWAGPGCNNHAARYSKCGCS \\
\hline Sp-AMP 3 & METKRLAYVMFVLVCLFLAMAQPSEGSYFTAWAGPGCNNHAARYSKCGCS \\
\hline $\mathrm{Sp}-\mathrm{AMP} 1$ & METKRLAYVMFVLVCLFLAMAQPSEGSYFTAWAGPGCNNHAARYSKCGC \\
\hline \multirow[t]{2}{*}{ MiAMP1 } & MASTKLFFSVITVMMLIAMASEMVNGSAFTVWSGPGCNNRAERYSKCGC \\
\hline & 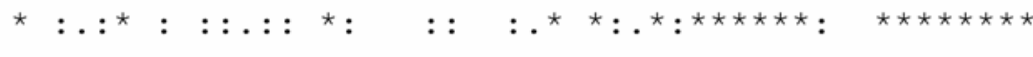 \\
\hline PmAMP1 & EFVYQGQTAAAYNTDNCKGVAQTRFSSSVNQACSNFGWKSVFIQC 105 \\
\hline Sp-AMP2 & EFMYQGQTAAAYNTDNCKGVAQTRFSSSVNQACSSFGWKSFFIQC 105 \\
\hline $\mathrm{Sp}-\mathrm{AMP} 4$ & EFMYQGQTAAAYNTDNCKGVAQTRFSSSVNQACSSFGWKSFFIQC 105 \\
\hline Sp-AMP 3 & EFMYQGQTASAYNTDNCKGVAQTRFSSSVNQACSSFGWKSFFIQC 105 \\
\hline $\mathrm{Sp}-\mathrm{AMP} 1$ & EFVYQGQTASAYNTANCKGVAQTRFSGSVNQACSGFGWKSFFIQC 105 \\
\hline MiAMP1 & DFSYTGQTAALYNQAGCSGVAHTRFGSSA-RACNPFGWKSIFIQC 102 \\
\hline & 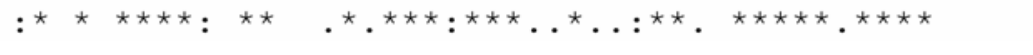 \\
\hline
\end{tabular}

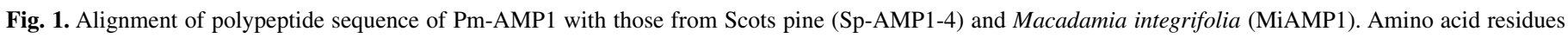
conserved in all of the compared are highlighted with asterisks. Conserved and semiconserved substitutions are represented by colons and dots, respectively. 
WWP blister rust pathosystem, an antibody probe was initially produced to a synthetic N-terminal peptide (3): this being the only Pm-AMP1 sequence information known at the time. Unfortunately, the antibody reacted poorly to bark protein samples that contained Pm-AMP1 (data not shown). Later, having obtained the full-length Pm-AMP1 cDNA sequence, the entire deduced amino acid sequence was analyzed for potential antigenic sites using the DNASTAR Program (DNASTAR Inc., Madison, WI) with the Jameson-Wolf module (12). This analysis revealed three regions along the primary sequence containing potential antigenic epitopes. A polyclonal antibody was produced against one of these sites, which is also mostly hydrophilic. The antigenic index analysis also showed the N-terminal region to be the least antigenic of Pm-AMP1. Figure 3 demonstrates that this antibody reacts primarily to a single band in crude bark protein extracts of WWP.

Detection of Pm-AMP1 in infected WWP trees. Quantities of Pm-AMP1 in bark samples of mature WWP that were collected in April 1991, February 1993, October 1993, and May 1994 from four resistant (free from cankers) and four susceptible (with active cankers) white pine trees are shown (Fig. 4). The level of PmAMP1 was generally higher in cankered, susceptible trees in all months except April. In May, Pm-AMP1 expression was significantly higher in susceptible trees compared with resistant trees $(P=0.0001)$, indicative of Pm-AMP1 elevation as a result of infection by the white pine blister rust fungus. Two-way ANOVAs for independent samples were performed to determine statistical significance between sample sets.

Two-year-old WWP seedlings from susceptible and SCG families were sampled in the summer. These showed mean Pm-AMP1 levels that were significantly higher in older needles and twigs and barely detectable in current-year tissues $(P<0.001$ for each tissue type) (Fig. 5). Additionally, the level of Pm-AMP1 was consistently higher in both needles and twigs from SCG seedlings than in needles and twigs from susceptible seedlings. In needles (Fig. 5A and B), there was a significant difference in mean PmAMP1 content $(P=0.004)$ between 2-year-old susceptible and 2-year-old SCG-resistant samples. In twigs (Fig. 5C and D), the differences in mean Pm-AMP1 content between susceptible and SCG-resistant samples were significant for both 1- and 2-year-old tissues $(P=0.0082)$.

In winter samples of the same seedlings, Pm-AMP1 content in SCG-resistant needles was significantly higher than in susceptible

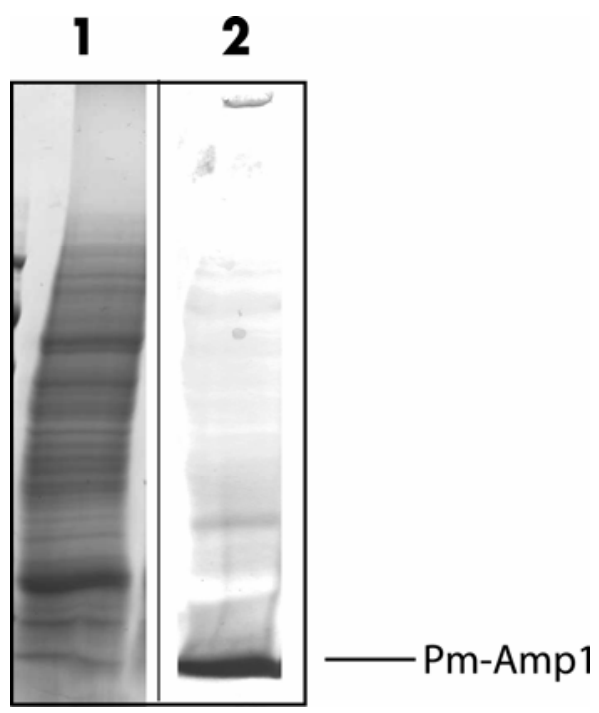

Fig. 3. Analysis of Pm-AMP1 antibody specificity. Coomassie stained gel of white pine crude protein extract (lane 1). Western immunoblot of white pine crude extract (lane 2) probed with Pm-AMP1 polyclonal antibody. Each lane was loaded with $50 \mu \mathrm{g}$ of protein. needles for each year of growth $(P<0.0001)$ (Fig. 6A). This elevated Pm-AMP1 expression in needles from SCG-resistant seedlings was more pronounced in the winter (Fig. 6A) than in the summer (Fig. 5B). Unlike the summer samples, Pm-AMP1 was detectable at high levels in current-year needles and twigs during the winter (Fig. 6A and B). In winter twigs, the only significant difference observed was between 1-year-old SCG-resistant and 1-year-old susceptible samples $(P=0.02)$ (Fig. 6B). These data show that the overall levels of Pm-AMP1 are generally higher in SCG-resistant tissues and that a seasonal and age-related effect on Pm-AMP1 expression also exists.

In summer and winter, stem bark tissue was sampled only from cankered, susceptible 2-year-old seedlings and not from resistant ones, as this would have destroyed seedlings saved for orchard propagation (Fig. 7). During the summer, there was no significant difference in Pm-AMP1 expression between cankered, marginal, and healthy bark $(P>0.05)$. However, in winter, we observed a gradual decline in the amount of Pm-AMP1 being synthesized in tissues sampled from healthy bark near the canker margin to within the cankered tissue (Fig. 7A). The decrease in mean PmAMP1 synthesis within the cankered tissue as opposed to that within the healthy bark was statistically significant $(P=0.02)$ (Fig. 7B).

Wounding and chemical treatment. Pm-AMP1 could also be induced (Fig. 8) by treatment with methyl jasmonate or by local wounding. Current-year needles collected from several resistant seedlings were subjected to these treatments indicating that PmAPM1 is a typical defense response protein.

\section{DISCUSSION}

Previous work on proteomic analysis of bark proteins from WWP revealed qualitative and quantitative differences between C. ribicola-resistant and -susceptible trees (3). One of these proteins, a 10.6-kDa polypeptide, was found enriched in receding canker margins of SCG-resistant trees. In this study, cloning and characterization of this protein (Pm-AMP1) revealed that it belongs to a new family of AMPs. Pm-AMP1 has significant homology to MiAMP1 isolated from Macademia integrifolia and putative AMPs from Pinus sylvestris. Not surprisingly, Pm-AMP1 has strongest homology to AMPs from a related Pinus species (1). All three AMPs belonging to this family have six conserved cysteine residues.

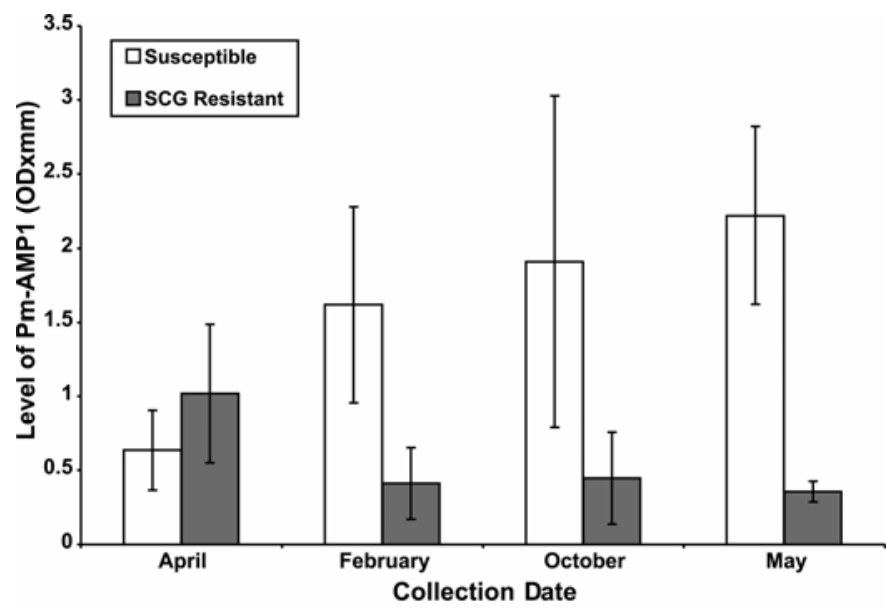

Fig. 4. Immuno-quantification of Pm-Amp1 content in susceptible and resistant tree bark. Relative amounts of Pm-AMP1 protein in mature (31 to 33 years old) bark tissue collected from susceptible (distal to cankered tissue) and resistant (devoid of canker) western white pine trees during April 1991, February 1993, October 1993, and May 1994. Bars represent mean Pm-AMP1 content $( \pm \mathrm{SE})$ of four susceptible and four resistant samples. 

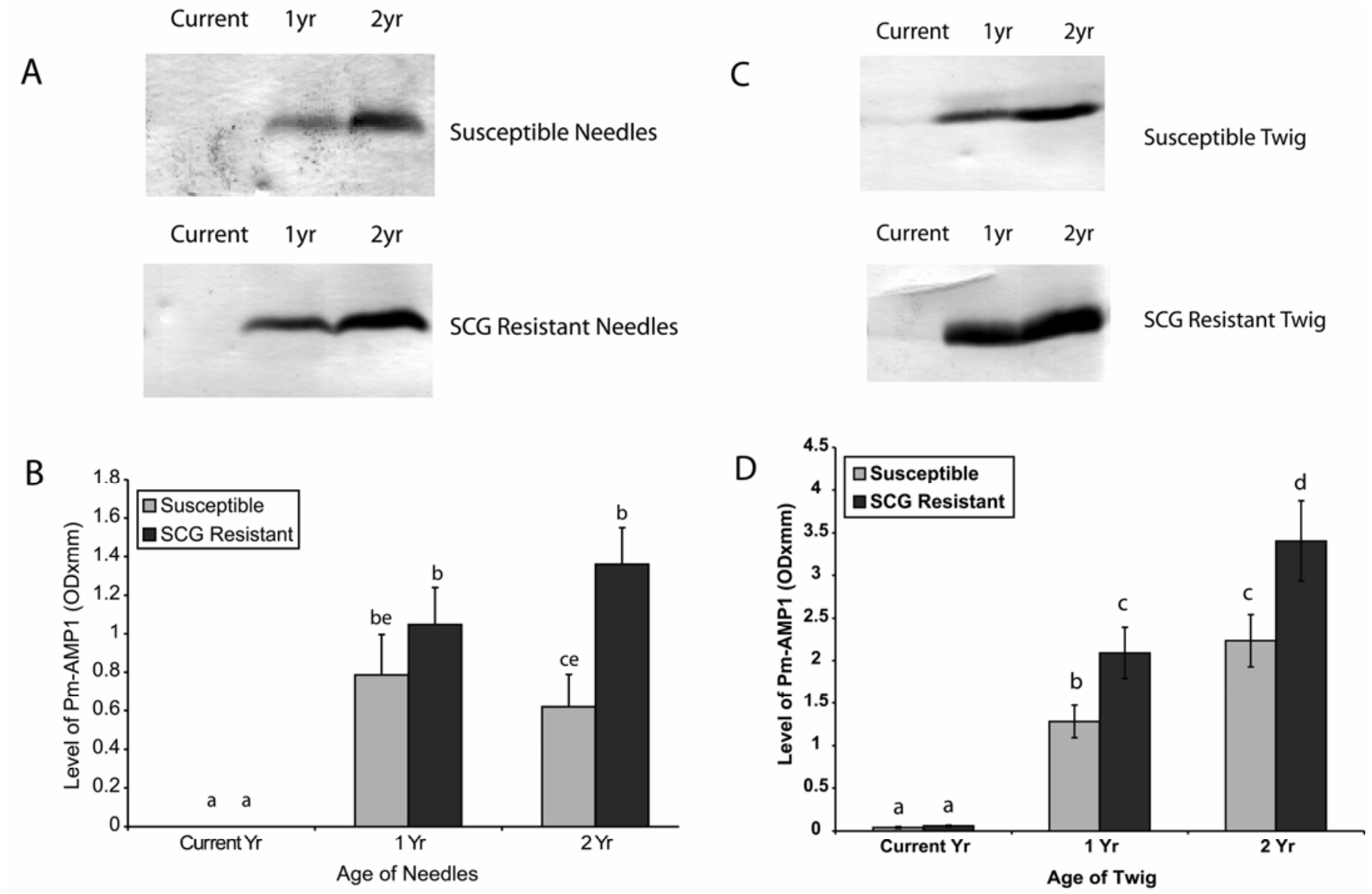

Fig. 5. Immuno-quantification of Pm-AMP1 content in susceptible and resistant needles and twigs during summer. Summer tissue samples of susceptible and slow-canker-growth (SCG)-resistant western white pine needles (A) and twigs (C) representing 3 years of growth were probed with Pm-AMP1 antibody. Quantitative analysis of Pm-AMP1 levels in $\mathbf{A}$ and $\mathbf{C}$ are shown in $\mathbf{B}$ and $\mathbf{D}$, respectively. Significant differences $(P<0.05)$ in mean Pm-AMP1 accumulation $( \pm \mathrm{SE})$ between susceptible and SCG tissues in each year of growth are indicated by different letters, according to Tukey's analysis.

Molecular characterization of this protein also revealed more reactive antigenic sites for antibody synthesis, and a new antibody was generated to the region between Y46 and C67 located in the second $\beta$-sheet of Pm-AMP1 (Fig. 2B). This new antibody reacted strongly to the target protein. Having an antibody specific to Pm-AMP1 made it possible to further investigate the role of PmAMP1 in the WWP-blister rust pathosystem. Western blot analysis of mature trees showed elevated Pm-AMP1 levels following infection with the fungus. In mature tree bark, a higher level of Pm-AMP1 was observed in susceptible bark tissues relative to resistant (i.e., devoid of cankers) bark tissues. However, in 2-yearold seedlings, a higher level of Pm-AMP1 was observed in SCGresistant twig/needle tissues relative to tissues sampled from susceptible seedlings. This apparent contradictory finding may be due to the unknown nature of resistance in the mature trees while the resistant young seedlings are known to be SCG. These mature trees were classified as resistant because they were devoid of cankers, whereas mature trees with cankers were classified as susceptible. The observation of relatively high levels of PmAMP1 in foliage of SCG-resistant trees suggests regulation of the Pm-AMP1 gene may be linked to genetic elements that underlie this type of resistance and should be exploited to develop marker(s) for breeding this phenotype.

Ontogenic resistance is involved in needle tissues of varying maturity in the white pine blister rust pathosystem. Cotyledons and primary needles are extremely susceptible to blister rust pathogen infection (7). The role of Pm-AMP1 in this ontogenic resistance needs to be investigated. These factors may explain why barely detectable levels of Pm-AMP1 were observed in current-year needles and twigs sampled in the summer (Fig. 5).

A thorough investigation would be required to see how season and age affect Pm-AMP1 expression.

As we have previously shown that a WWP PR-10 protein was also up-regulated during winter months (6), it was of interest to examine the difference in the level of Pm-AMP1 in infected WWPs in both summer and winter. The low level of Pm-AMP1 observed within cankers or near canker margins of samples collected from susceptible trees only in winter months (Fig. 7B) suggests seasonal factors such as low photoperiod and cooler temperatures in winter may contribute to the pathogen overcoming the host's defense response.

Both mechanical wounding and methyl jasmonate treatment of healthy white pine foliage also induced Pm-AMP1, much the same way as chemical treatment and wounding can induce other AMPs such as defensin and thionin (8). These results suggest that Pm-AMP1 plays a role in the host's defense response.

The mode of action of Pm-AMP1, however, remains unknown. Other research suggests that cationic AMPs may act on the fungal cell wall or on enzymes involved in the synthesis of cell wall components, that they may interact with the lipid bilayer of plasma membranes, creating pores that allow leakage of electrolytes, or that they simply may interact with intracellular targets (20). Based on its pI value, we assume that Pm-AMP1 has cationic properties under physiological conditions. Interestingly, the simulated structure of Pm-AMP1 resembled that of MiAMP1. A three-dimensional structure obtained by nuclear magnetic reso- 

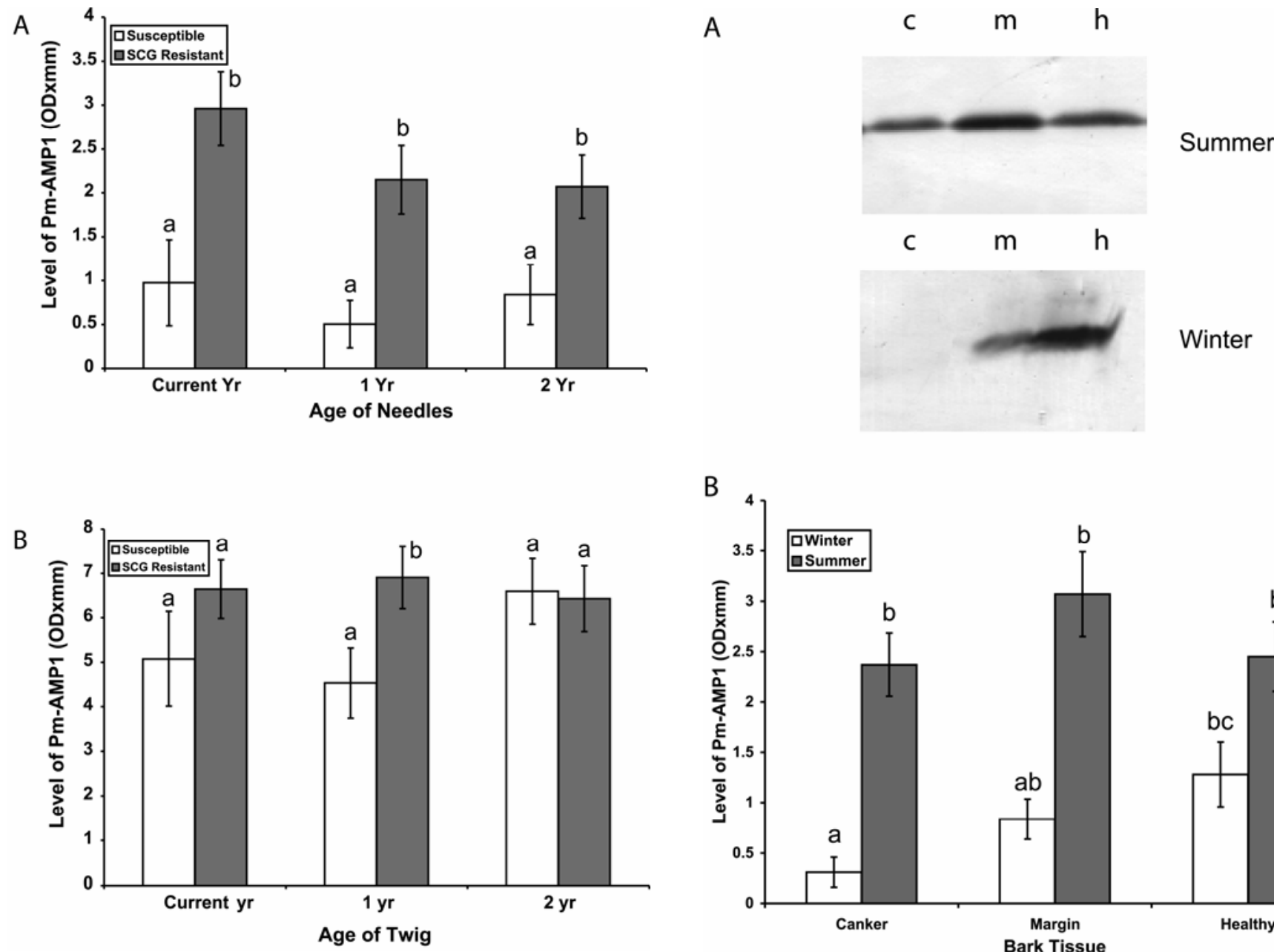

Fig. 6. Immuno-quantification of Pm-AMP1 content of Pm-AMP1 levels in susceptible and resistant needles and twigs during winter. Level of Pm-AMP1 in winter tissue samples of susceptible and slow-canker-growth (SCG)-resistant western white pine needles (A) and twigs (B) from 2-year-old seedlings. Significant differences $(P<0.05)$ in mean Pm-AMP1 accumulation $( \pm$ SE) between susceptible and SCG tissues in each year of growth are indicated by different letters, according to Tukey's analysis.

nance spectroscopic data revealed that MiAMP1 is similar to a yeast-killing toxin from Wiiliopsis mrakii that inhibits synthesis of glucan, a fungal cell wall component (17). A simulated threedimensional structure of Pm-AMP1 revealed interesting features in common with the cationic properties of AMPs.

The structurally related MiAMP1 has shown in vitro inhibitory activity against a variety of fungal, oomycete, and bacterial phytopathogens as well as human mycopathogens (16). The high level of inhibition (95\%) exhibited by MiAMP1 at low concentrations $(5 \mu \mathrm{g} / \mathrm{ml})$ makes it a potent inhibitor of some microbial plant pathogens and highly comparable to other AMPs (16). To demonstrate antifungal properties of Pm-AMP1, work continues to express its recombinant form for use in $C$. ribicola inhibition assays.

\section{ACKNOWLEDGMENTS}

This work was supported by Canadian Forest Service Genomics and British Columbia Forest Investment Account Funds awarded to A. K. M. Ekramoddoullah. We thank M. Chong and D. Patel for technical assistance. Purified Macadamia integrifolia MiAMP1 peptide and crude serum were provided by K. Goulter of the University of Queensland, Brisbane, Australia. We thank E. Allen, P. Dale, and L. Safranyik for reviewing, and $\mathrm{M}$. Keiran for editing the manuscript.

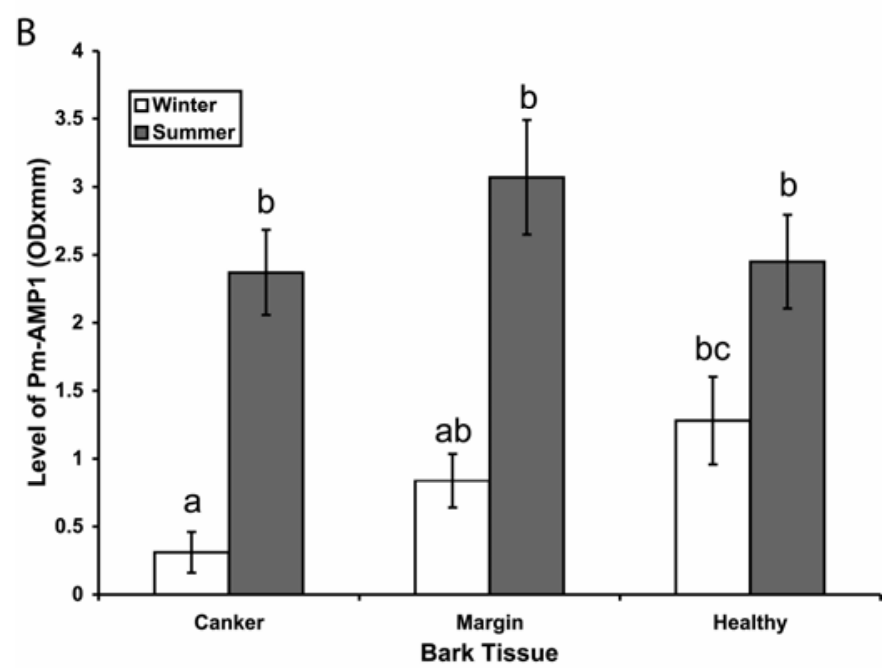

Fig. 7. Immuno-quantification of seasonal PmAMP-1 levels in cankers and surrounding tissue. A, PmAMP-1 protein content in cankered (c), marginal (m), and healthy (h) stem bark of susceptible western white pine sampled in summer and winter. B, Mean PmAMP-1 accumulation $( \pm$ SE) in susceptible bark. Different letters indicate significant differences between bark tissues $(P<0.05)$, according to Tukey's analysis.

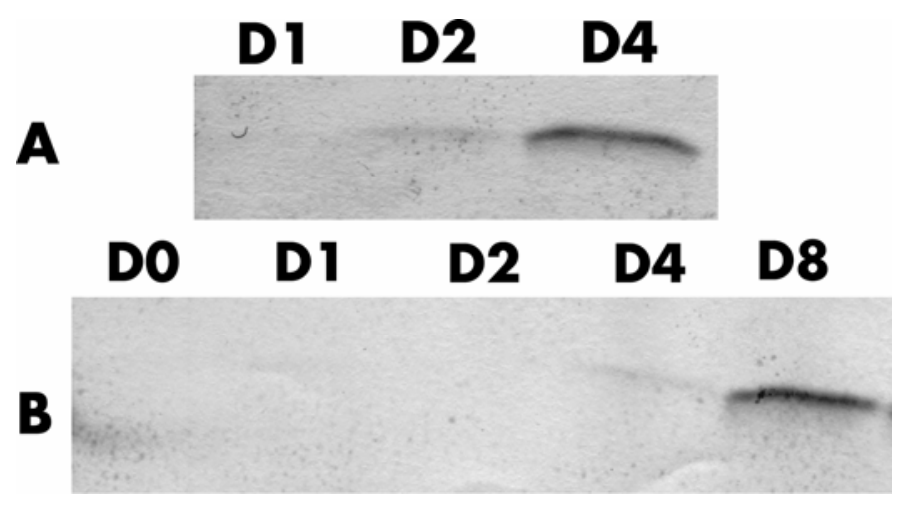

Fig. 8. Effect of methyl jasmonate and wounding treatments on Pm-AMP1 levels. Pm-AMP1 levels in needles after treatment with A, methyl jasmonate or $\mathbf{B}$, local wounding 0 to 8 days (D0 to D8) posttreatment are shown. The Pm-AMP1 protein was detected by western immunoblot.

\section{LITERATURE CITED}

1. Asiegbu, F. O., Choi, W., Li, G., Nahalkova, J., and Dean, R. A. 2003. Isolation of a novel antimicrobial peptide gene $(S p-A M P)$ homologue from Pinus sylvestris (Scots pine) following infection with the root rot fungus Heterobasidion annosum. FEMS Microbiol. Lett. 228:27-31. 
2. Broekaert, W. F., Cammue, B. P. A., DeBolle, M. F. C., Thevissen, K., DeSamblanx, G. W., and Osborn, R. W. 1997. Antimicrobial peptides from plants. Crit. Rev. Plant Sci. 16:297-323.

3. Davidson, J. J., and Ekramoddoullah, A. K. M. 1997. Analysis of bark protein in blister rust-resistant and susceptible western white pine (Pinus monticola). Tree Physiol. 17:663-669.

4. Dronzek, J. 1995. Western white pine improvement programme for British Columbia. Pages 28-32 in: Proc. 25th Meeting of the Canadian Tree Improvement Association: Part I. Evolution and Tree Breeding. J. Laverau, ed. Natural Resources Canada, Fredericton, NB.

5. Ekramoddoullah, A. K. M., and Davidson, J. J. 1995. A method for the determination of conifer foliage protein extracted using sodium dodecyl and mercaptoethanol. Phytochem. Anal. 6:20-24.

6. Ekramoddoullah, A. K. M., Davidson, J. J., and Taylor, D. 1998. A protein associated with frost hardiness of western white pine is up-regulated by infection in the white pine blister rust pathosystem. Can. J. For. Res. 28:412-417.

7. Ekramoddoullah, A. K. M., and Hunt, R. S. 2002. Challenges and opportunities in studies of host-pathogen interactions in forest tree species. Can. J. Plant Pathol. 24:408-415.

8. Epple, P., Vignutelli, A., Apel, K., and Bohlmann, H. 1998. Differential induction of the Arabidopsis thaliana Thi2.1 gene by Fusarium oxysporum f. sp. matthiolae. Mol. Plant-Microbe Interact. 11:523-529.

9. Hoff, R. J., and McDonald, G. I. 1980. Improving rust-resistant strains of inland western white pine. U.S. Dep. Agric. For. Serv. Res. Paper INT245, Ogden, UT.

10. Hunt, R. S. 1988. White pine improvement in British Columbia. Pages 32-36 in: Proceedings of a Western White Pine Management Symposium. R. S. Hunt, ed. B.C. Forestry Canada, Pacific Forestry Centre, Victoria, BC.
11. Hunt, R. S. 1997. Relative value of slow canker growth and bark reaction as resistance responses to white pine blister rust. Can. J. Plant Pathol. 19:352-357.

12. Jameson, B. A., and Wolf, H. 1988. The antigenic index: A novel algorithm for predicting antigenic determinants. CABIOS. 4:184-186.

13. Kinloch, B. B., Sniezko, R. A., Barnes, G. D., and Greathouse, T. E. 1999. A major gene for resistance to white pine blister rust in western white pine from the western Cascade Range. Phytopathology 89:861-867.

14. Liu, J.-J., Ekramoddoullah, A. K. M., and Yu, X. 2003. Differential expression of multiple PR10 proteins in western white pine following wounding, fungal infection and cold-hardening. Physiol. Plantarum 119:544-553.

15. Maloy, O. C. 1997. White pine blister rust control in North America: A case history. Annu. Rev. Phytopathol. 35:87-109.

16. Marcus, J. P., Goulter, K. C., Green, J. L., Harrison, S. J., and Manners, J. M. 1997. Purification, characterisation and cDNA cloning of an antimicrobial peptide from Macadamia integrifolia. Eur. J. Biochem. 244:743-749.

17. McManus, A. M., Nielsen, K. J., Marcus, J. P., Harrison, S. J., Green, J. L., Manners, J. M., and Craik, D. J. 1999. MiAMP1, a novel protein from Macadamia integrifolia adopts a Greek key-barrel fold unique amongst plant antimicrobial proteins. J. Microbiol. 293:629-638.

18. Sambrook, J., and Russell, D. W. 1989. Molecular Cloning: A Laboratory Manual. Cold Spring Harbor Laboratory, Cold Spring Harbor, NY.

19. Schwede, T., Kopp, J., Guex, N., and Peitsch, M. C. 2003. SWISSMODEL: An automated protein homology-modeling server. Nucleic Acids Res. 31:3381-3385.

20. Theis, T., and Stahl, U. 2004. Antifungal proteins: Targets, mechanisms and prospective applications. Cell. Mol. Life Sci. 61:437-455. 